\title{
O ensino da leitura e escrita e o livro didático na Educação Infantil
}

\author{
The teaching of reading and writing and the textbook in Early Childhood Education
}

\author{
La enseñanza de la lectura y escritura y el libro de texto en la Educación Infantil
}

ana Carolina Perrusi Alves Brandão*

ALEXSANDRO DA SILVA**

\begin{abstract}
$\longrightarrow \prec$
RESUMO

O presente artigo discute dois temas polêmicos: o ensino da leitura e da escrita na Educação Infantil e a adoção de livros didáticos nessa etapa da Educação Básica. Para isso, apresenta, inicialmente, algumas reflexões sobre esses dois tópicos, identificando e discutindo diferentes posições assumidas nesse debate. Em um segundo momento, os dois temas são retomados na análise de propostas extraídas do "Meu Livro de Atividades" (Pré II), um dos materiais do Programa Alfa e Beto Pré-Escola dirigido ao ensino de leitura e escrita para crianças de 5 anos. O artigo contribui, portanto, para a tomada de decisões pedagógicas mais informadas no campo da Educação Infantil.
\end{abstract}

Palavras-chave: Educação Infantil. Livro didático. Leitura e escrita.

\begin{abstract}
This article discusses two controversial issues: the teaching of reading and writing in early years education and the introduction of text books at this educational stage. We present some reflections on these topics, identifying and discussing different positions in the debate. Secondly, the two themes are pursued in an analysis of activities proposed by "Meu Livro de Atividades (Pré II)", one of the materials of the "Alfa e Beto" Preschool Program which aims to teach reading and writing to 5-year-old children. The article contributes, therefore, to more informed educational decisions in the field of Early Childhood Education.
\end{abstract}

Keywords: Early Childhood Education. Textbook. Reading and writing.

\section{RESUMEN}

El presente artículo discute dos temas polémicos: la enseñanza de la lectura y la escritura en la Educación Infantil y la adopción de libros de texto en esta etapa de la Educación Básica. Así pues, se presenta, inicialmente, algunas reflexiones asumidas en ese debate. En un segundo momento, los dos temas serán retomados en un análisis de las proposiciones extraídas del manual "Meu Livro de Atividades (Pré II)", uno de los materiales del Programa "Alfa e Beto" Pre-Escuela direccionado a la enseñanza de la lectura y escritura a los niños de 5 años. El artículo contribuye, por tanto, a la toma de decisiones pedagógicas mejor informadas en el ámbito de la Educación Infantil.

Palabras clave: Educación Infantil. Libro de texto. Lectura y escritura.

\footnotetext{
* Mestre em Psicologia Cognitiva pela Universidade Federal de Pernambuco e PhD em Psicologia pela University of Sussex. Pós-doutorado na University of Oxford.E-mail: < carol.perrusi@ufpe.br>.

**Graduado em Pedagogia. Mestre e doutor em Educação pela Universidade Federal de Pernambuco - UFPE, com período sanduíche no Institut National de Recherche Pédagogique - INRP, Paris.E-mail:<alexs-silva@uol.com.br>.
} 


\section{INTRODUÇÃO}

$\mathrm{O}$ artigo discute, de maneira articulada, dois temas polêmicos na Educação Infantil: o uso de livros didáticos e o ensino da leitura e da escrita. Tratam-se de temas complexos, porque, como veremos adiante, não há um consenso sobre a necessidade ou a pertinência da adoção de livros escolares nessa etapa de ensino, nem sobre o lugar da leitura e da escrita no currículo destinado a crianças menores de 6 anos.

Com a intenção de contribuir com esse debate, apresentaremos, inicialmente, diferentes perspectivas no que se refere a esses dois temas. Em seguida, com vistas a ilustrar a discussão empreendida, tomaremos como exemplo a proposta do "Programa Alfa e Beto Pré-Escola" para o ensino da leitura e da escrita, com base em atividades extraídas do material que constitui o carro-chefe do Programa, o "Meu Livro de Atividades".

\section{LIVROS DIDÁTICOS NA EDUCAÇÃO INFANTIL: USÁ-LOS OU NÃO?}

O livro didático é, sem dúvida, um dos recursos mais utilizados, no Brasil, nas salas de aula do Ensino Fundamental e também do Ensino Médio. Mais recentemente, é perceptível o espaço que esse recurso didático também tem ocupado na Educação Infantil. De fato, alguns estudos (CRUZ, 2012; NASCIMENTO, 2012) mostram que, nos últimos anos, livros didáticos e sistemas apostilados ${ }^{1}$ têm sido, cada vez mais, adotados por escolas privadas de Educação Infantil e até mesmo por muitas redes públicas de ensino ${ }^{2}$.

Adotar ou não livros didáticos na Educação Infantil é, porém, um tema que exige uma reflexão cuidadosa por parte de professores, gestores de escolas e formuladores de políticas públicas. De um lado, há os que argumentam que a adoção desse recurso seria importante para, na ausência de um currículo, garantir certa uniformidade em relação aos conteúdo a serem ensinados na escola. Segundo essa perspectiva, ouso do livro garantiria um conjunto mínimo de conhecimentos que poderiam ser acessados por todas as crianças. Nessa mesma linha de raciocínio, materiais estruturados também poderiam dar maior segurança a professores com pouca experiência ou mesmo suprimir certas lacunas de sua formação, na

\footnotetext{
${ }^{1}$ É necessário salientar que, em muitos casos, o livro didático faz parte de um kit que inclui outros recursos pedagógicos e uma proposta de formação e monitoramento para os professores que usarão esses recursos. Por exemplo, no caso do "Sistema Aprende Brasil", da Editora Positivo, comprado pela Prefeitura do Recife (Pernambuco) em 2014, além dos livros didáticos, o kit inclui mesas tecnológicas, manuais para uso das mesas, acesso ao portal do Sistema com propostas de atividades e acompanhamento aos professores.

2 Na verdade, o uso de livros didáticos na Educação Infantil em escolas da rede privada de ensino não é recente e data, pelo menos, dos anos 1990.
}

medida em que seriam uma fonte de atividades e temas para o trabalho pedagógico. Outra vantagem também atribuída aos livros didáticos seria a possibilidade que as famílias teriam de acompanhar os conteúdos abordados e as atividades desenvolvidas na escola e, particularmente no caso da Educação Infantil, a adoção desse recurso responderia à ansiedade de alguns pais de que seus filhos não estariam "apenas brincando" no espaço escolar.

Contrários aos argumentos expostos acima, outros defendem que o uso do livro didático na Educação Infantil diminuiria a possibilidade de tratar os temas de forma mais contextualizada, partindo de interesses genuínos e particulares de um determinado grupo de crianças. De acordo ainda com essa posição, os livros didáticos também poderiam contribuir para embotar a autonomia e a sensibilidade do professor para captar possíveis interesses das crianças, poisos temas a serem tratados já estariam previamente determinados, as atividades prontas e a eles caberia apenas seguir as orientações prescritas nos manuais. Em síntese, a adoção desse recurso didático tenderia, nessa perspectiva, a padronizar e empobrecer as experiências que poderiam ser vivenciadas na escola, tanto para as crianças, quanto para os professores.

Outro argumento contrário à adoção dos livros seria a quantidade de atividades com lápis e papel que crianças tão pequenas passariam a ter que realizar. Em outras palavras, para fazer todas as atividades e chegar ao final do livro, elas precisariam ficar mais tempo sentadas em suas mesinhas, atendendo aos comandos do material e da professora. Dessa forma, o livro contribuiria para a restrição do trabalho em outras esferas essenciais para o desenvolvimento infantil, como, por exemplo, o contato com a natureza, o movimento por meio de jogos corporais, as brincadeiras de faz de conta, a escuta e a conversa sobre histórias ouvidas ou experiências vivenciadas pelas crianças, entre outras.

De fato, ao analisar a Coleção Buriti Mirim para Educação Infantil, lançada pela Editora Moderna em 2010 e frequentemente adotada em escolas privadas de Recife-PE, Lorenzo (2014) destaca o excessivo número de atividades presentes nos livros dessa coleção: 174 nos volumes 1 e 2, para crianças de 3 e 4 anos, respectivamente, e 218 no volume 3, para as crianças de 5 anos. Apesar de ressaltar a boa qualidade gráfica da coleção e a adequação das unidades temáticas aos interesses infantis, a autora aponta a reduzida variedade dos tipos de atividades propostos e o seu pequeno potencial para ampliar o que as crianças possivelmente já sabem.

Resultado semelhante também foi encontrado por Brandão e Selva (1999) ao analisarem as propostas de resolução de problemas em 12 coleções de livros de matemática voltados para crianças entre 4 e 6 anos de idade. Segundo as autoras, a estrutura dos problemas 
tendia a seguir um único modelo, apresentando situações repetitivas e contribuindo pouco para o desenvolvimento de estratégias de solução diversificadas ou o confronto entre diferentes possibilidades de resposta.

O estudo de Cruz (2013), que analisou o trabalho voltado para o desenvolvimento do conceito de "classificação" em livros didáticos recentemente publicados para o segmento da Educação Infantil, concluiu algo semelhante. Segundo a autora, as atividades de classificação também eram pouco variadas e não apresentavam desafios às crianças. Assim, na maioria dos casos, elas não eram incentivadas a propor um critério de classificação, pois apenas precisavam seguir o critério já indicado no livro.

Considerando o segundo bloco de argumentos apresentados anteriormente, assumimos a posição de que o uso de livros didáticos não é imprescindível na Educação Infantil e que, antes de tomar a decisão de adotar livros e sistemas apostilados nessa etapa da Educação Básica, é fundamental discutir uma série de questões, como, por exemplo: Qual a qualidade dos livros didáticos e sistemas apostilados disponíveis no mercado? Que concepções de ensino e aprendizagem veiculam? Que impactos podem imprimir na rotina das crianças na Educação Infantil? Esses materiais podem, de fato, contribuir para a melhoria da qualidade do trabalho pedagógico?

Ao que parece, nossa posição é compartilhada pelo Ministério da Educação, já que a Educação Infantil não tem sido incluída no Programa Nacional do Livro Didático (PNLD), responsável pela avaliação, aquisição e distribuição gratuita de livros didáticos às escolas públicas do país que atendem ao Ensino Fundamental, ao Ensino Médio e à Educação de Jovens e Adultos. No caso da Educação Infantil, o MEC não distribui livros didáticos, mas, sim, acervos de obras literárias, por meio do Programa Nacional Biblioteca na Escola (PNBE), o que, consideramos uma iniciativa inteiramente apropriada.

Como anunciamos anteriormente, outro tema que tem sido objeto de muitas controvérsias no campo da Educação Infantil diz respeito ao lugar do ensino da leitura e da escrita no currículo destinado às crianças menores de 6 anos. É sobre esse tema que discutiremos a seguir, refletindo sobre algumas perspectivas em torno da presença ou não desse ensino no currículo da primeira etapa da Educação Básica.

\section{O ENSINO DA LEITURA E DA ESCRITA NA EDUCAÇÃO INFANTIL: PERSPECTIVAS EM DISCUSSÃO}

O ensino da leitura e da escrita na Educação Infantil é, ainda hoje, objeto de muitas controvérsias no contexto brasileiro. Há, por um lado, aqueles que advogam a presença desse ensino na primeira etapa da Educação Básica, considerando que as crianças deveriam ser alfabetizadas antes dos 6 anos de idade. Por outro lado, há aqueles que assumem uma posição diametralmente oposta, defendendo apenas (ou quase exclusivamente) o trabalho com outras linguagens (corporal, visual, musical, etc.) na educação da primeira infância. Entre essas duas posições extremas, existem, evidentemente, perspectivas intermediárias, como a que assumiremos mais adiante.

No caso da primeira posição, que Brandão e Leal (2010) designaram de "obrigação da alfabetização", o ensino da leitura e da escrita caracteriza-se, inicialmente, por um "período preparatório" para a alfabetização, no qual as crianças são treinadas em atividades de coordenação motora e de discriminação visual e auditiva, supostos pré-requisitos para aprender a ler e a escrever. Em seguida, após serem consideradas "prontas" para serem alfabetizadas, elas (as crianças) são submetidas, principalmente, a atividades de cópia, repetição e reconhecimento de letras ou fonemas isolados, sílabas e palavras. Segundo Ferreiro (1995, p.97), quando se decide

[...] iniciar o aprendizado da leitura e da escrita antes do primário, vemos a sala de aula da préescola assemelhar-se notadamente à do primeiro ano primário, e a prática docente passa a seguir o modelo das mais tradicionais práticas do primário: exercício de controle motriz e discriminação perceptiva, reconhecimento e cópia de letras, sílabas ou palavras, repetições em coro... e nenhum uso funcional da língua escrita.

No segundo polo mencionado anteriormente, que Brandão e Leal (2010) nomearam de "letramento sem letras", considera-se inadequado o ensino da leitura e da escrita na Educação Infantil, sob o argumento de que esse ensino roubaria a infância das crianças. Essa perspectiva caracteriza-se pela

[...] ênfase dada a outros tipos de linguagem na Educação Infantil, como a corporal, a musical, a gráfica, entre outras, banindo-se a linguagem escrita do trabalho com crianças pequenas. Nesse tipo de abordagem, portanto, a alfabetização [...] não é concebida como objeto do trabalho educativo, sendo, em geral, tomada como um "conteúdo escolar" e, portanto, proibido para crianças da Educação Infantil (BRANDÃO e LEAL, 2010, p. 18).

No cenário brasileiro atual, observamos ainda uma outra possibilidade em relação ao tratamento da leitura e da escrita na Educação Infantil, a qual podemos chamar de "à deriva...". Isto é, a professora não planeja, nem propõe atividades específicas nessa área, mas acolhe a curiosidade 
das crianças sobre o tema, limitando-se a responder, por exemplo, às perguntas que elas formulam sobre como se escreve o seu nome ou sobre o que está escrito em um cartaz. Assim, nesse contexto, caberia às crianças mostrar seu interesse pelas letras e tomar a iniciativa sobre o que gostariam de aprender. A professora, por sua vez, deveria acompanhar esse interesse e estar disponível para atendê-lo.

Sobre o debate agora delineado, Ferreiro (1995) apontou, há muito tempo atrás, que a questão "deve-se ou não ensinar a ler e a escrever na Educação Infantil” é mal colocada. Segundo argumenta, essa pergunta parte do falso pressuposto de que são os adultos que decidem quando deveria ser iniciada a aprendizagem da leitura e da escrita, desconsiderando que, mesmo antes de entrar na escola, as crianças já iniciam esse processo de aprendizagem. Assim, para Ferreiro (1995, p. 102),

na pré-escola deveria permitir a todas as crianças a liberdade de experimentar os sinais escritos, num ambiente rico em escritas diversas, ou seja: escutar alguém lendo em voz alta e ver os adultos escrevendo; tentar escrever (sem estar necessariamente copiando um modelo); tentar ler utilizando dados contextuais, assim como reconhecendo semelhanças e diferenças nas séries de letras; brincar com a linguagem para descobrir semelhanças e diferenças sonoras.

Apoiando-nos nessa posição, mas indo além dela, consideramos que as crianças têm direito a ter acesso à linguagem escrita e à sua notação desde a Educação Infantil, respeitando-se suas necessidades e interesses (cf. BRANDÃO e ROSA, 2010). Nessa perspectiva, ler e escrever na Educação Infantil não significa, necessariamente, abdicar do importante espaço da brincadeira e da exploração de múltiplas linguagens, nem, muito menos, obrigar as crianças a serem alfabetizadas por meio de exercícios enfadonhos como os que citamos anteriormente. Assim, no que se refere à alfabetização, ressaltamos que:

não é função da Educação Infantil alfabetizar a criança, se entendermos por alfabetizar levar a criança a terminar essa etapa já sabendo ler e escrever com alguma segurança. Não é isso (embora isso possa acontecer, e tem efetivamente acontecido muitas vezes). [...] Na Educação Infantil, a criança deve pelo menos descobrir o princípio alfabético: descobrir que, quando escrevemos, registramos o som das palavras, e não a coisa sobre a qual estamos falando. Esse é o grande salto que a Educação Infantil tem de ajudar a criança a dar. (SOARES, 2011, n.p.).

Em resumo, no campo da linguagem escrita, entendemos, assim como Soares (2009) e Brandão e Leal
(2010), que tanto as atividades voltadas à apropriação do sistema de escrita, quanto ao letramento devem estar presentes na Educação Infantil. Em outras palavras, a leitura de histórias e de outros gêneros de texto, a produção de textos escritos e a reflexão sobre as palavras devem integrar o trabalho pedagógico desenvolvido nessa etapa de ensino, considerando os interesses e as especificidades das diferentes faixas etárias nesses primeiros anos de escola.

Finalmente, nesse cenário de embates e de divergências, propomo-nos a apresentar algumas reflexões sobre o ensino da leitura e da escrita no livro didático de Educação Infantil, um recurso que, como já afirmamos, tem ocupado um espaço, cada vez maior, na organização do trabalho pedagógico voltado às crianças menores de 6 anos. Para isso, ilustraremos a seguir nossas posições a partir de exemplos extraídos de um material pedagógico de um Programa que tem sido adotado por muitas escolas e redes públicas de ensino do país: o Programa Alfa e Beto Pré-Escola.

\section{O ENSINO DA LEITURA E DA ESCRITA NO Livro didÁtico do Programa AlFA E BETO PRÉ-Escola}

\section{Meu Livro de Atividades: considerações introdutórias}

O Programa Alfa e Beto Pré-Escola pertence ao Instituto Alfa e Beto (IAB), uma organização não governamental que oferece produtos e serviços voltados para Educação Infantil e anos iniciais do Ensino Fundamental. O Instituto disponibiliza materiais pedagógicos tanto para uso individual da criança, quanto para uso coletivo em sala de aula, bem como materiais para os professores e para as escolas e secretarias de educação.

O livro didático "Meu Livro de Atividades" é constituído por dois volumes, um para o Pré I e outro para Pré II. Porém, outros materiais como os cadernos de caligrafia ("Grafismo e Caligrafia: introdução" e "Grafismo e Caligrafia: letras de forma"), os "Minilivros", o "Livro Gigante", o "Meu livro de Arte", o "Meus primeiros traços", além de cartazes, cartelas de letras e fantoches dos personagens do Programa (Alfa e Beto), fazem parte do Programa.

No que se refere à quantidade de atividades propostas, o "Meu Livro de Atividades" traz 400 atividades para o Pré 1 e 480 atividades para o Pré II, o que consideramos um número absolutamente inaceitável para crianças pequenas que precisam vivenciar atividades variadas ao longo da semana, contemplando, de modo equilibrado, propostas mais livres e atividades mais dirigidas. No livro do Pré II, por exemplo, para concluir as 480 atividades, seria preciso realizar, conforme orientação constante 
na introdução do material, 12 atividades por semana (RODRIGUES, ROCHA, ARAÚJO e OLIVEIRA, 2010, p.V) só neste livro.

Entendemos que as atividades com lápis e papel ainda que possam estar incluídas na rotina semanal das crianças (cf. BRANDÃO e CARVALHO, 2010), não podem constituir o eixo do trabalho pedagógico na Educação Infantil, pois, conforme ressaltam as Diretrizes Curriculares Nacionais para a Educação Infantil (BRASIL, 2010), a ação pedagógica nessa etapa de ensino deve enfatizar as interações, as brincadeiras e o trabalho com diferentes linguagens. De fato, como observa Soares (2011, n.p.),

É na educação infantil que se formaliza a educação da criança. E uma das maneiras de fazer isso é criando um currículo que oriente a criança em sua progressiva inserção no mundo social, no mundo da natureza, e propicie oportunidades para que ela desenvolva linguagens, por meio de sua introdução no mundo da música, da expressão corporal, das representações simbólicas e também no mundo da escrita.

Porém, cabe perguntar: como é possível seguir essa perspectiva quando é preciso manter as crianças sentadas e concentradas em responder uma enorme quantidade de atividades com lápis e papel? Além disso, embora a proposta pedagógica contida na apresentação do "Meu Livro de Atividades", ressalte que: "Nessa faixa etária, aprender e brincar são sinônimos e, portanto, a forma privilegiada de a criança aprender é a lúdica e se manifesta em sua preferência por brincadeiras e jogos..." (RODRIGUES, ROCHA, ARAÚJO e OLIVEIRA,
2010, p. V), as atividades do livro em questão, além de numerosas são extremamente repetitivas. Por exemplo, o mesmo tipo de atividade exposto na Figura 1 é proposto, ao longo do livro, mudando apenas o fonema e a letra que se pretende que a criança memorize.

Reconhecemos que os pequenos gostam de ouvir as mesmas histórias, assistir aos mesmos vídeos, participar das mesmas brincadeiras, etc., porém, isso só ocorre porque gostam de experimentar diversas vezes uma situação conhecida que dá prazer, além do fato de que são eles próprios que elegem o que querem repetir. Trata-se, portanto, de algo muito diferente de solicitar que as crianças realizem as mesmas atividades em um livro didático, cujas propostas são definidas a priori e devem ser cumpridas numa ordem fixa, seguindo um planejamento rígido, como é o caso do Programa em foco. Tal repetição de atividades resultará, certamente, em desinteresse e cansaço das crianças.

$\mathrm{Na}$ proposta pedagógica desse material, ressaltase, também, que as atividades "devem ser usadas para desafiar a criança” (RODRIGUES, ROCHA, ARAÚJO e OLIVEIRA, 2010, p.V). Todavia, não se observa a materialização dessa orientação em atividades do livro. Ao contrário, há um excesso de propostas nas quais as crianças devem responder mecanicamente, sem qualquer necessidade de pensar no que estão lendo ou grafando.

É o que podemos observar, por exemplo, na atividade da Figura 2, na qual as crianças são solicitadas a ligar letras iguais. Essa proposta, que se resume à discriminação visual de símbolos iguais e diferentes, não contribui sequer para o reconhecimento de que uma mesma letra pode apresentar diferentes formatos.

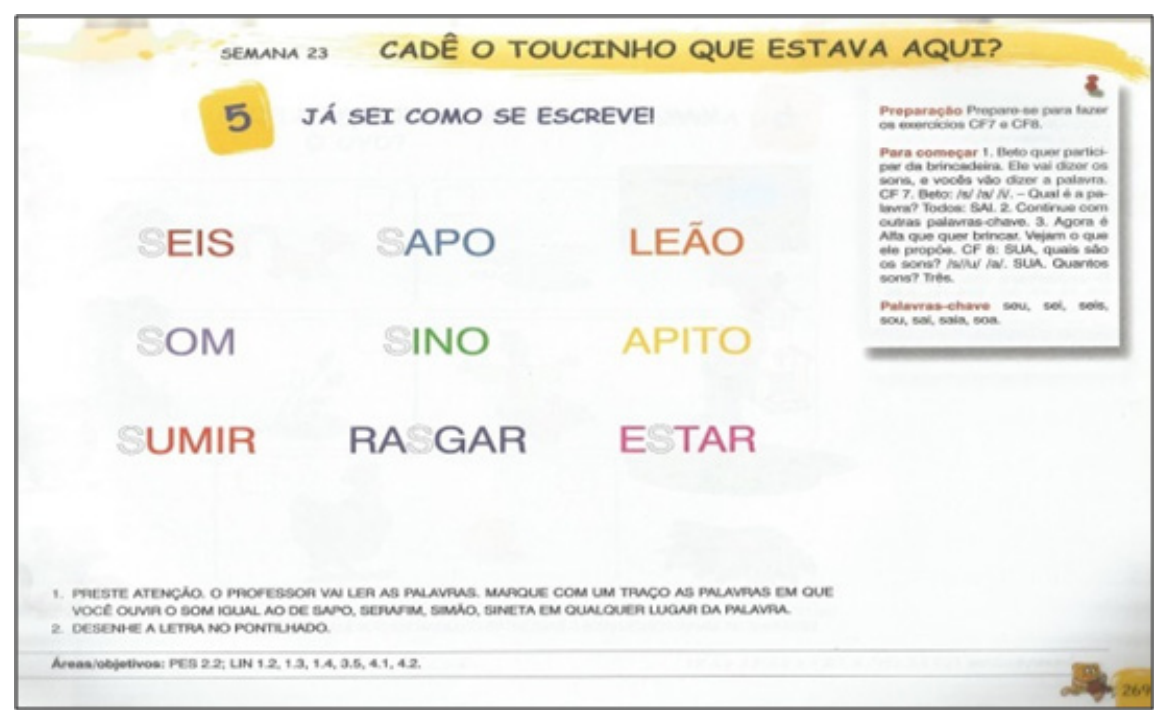

Fonte: Rodrigues, Rocha, Araújo e Oliveira (2010, p. 269).

Figura 1. Ficha do Meu Livro de Atividades 


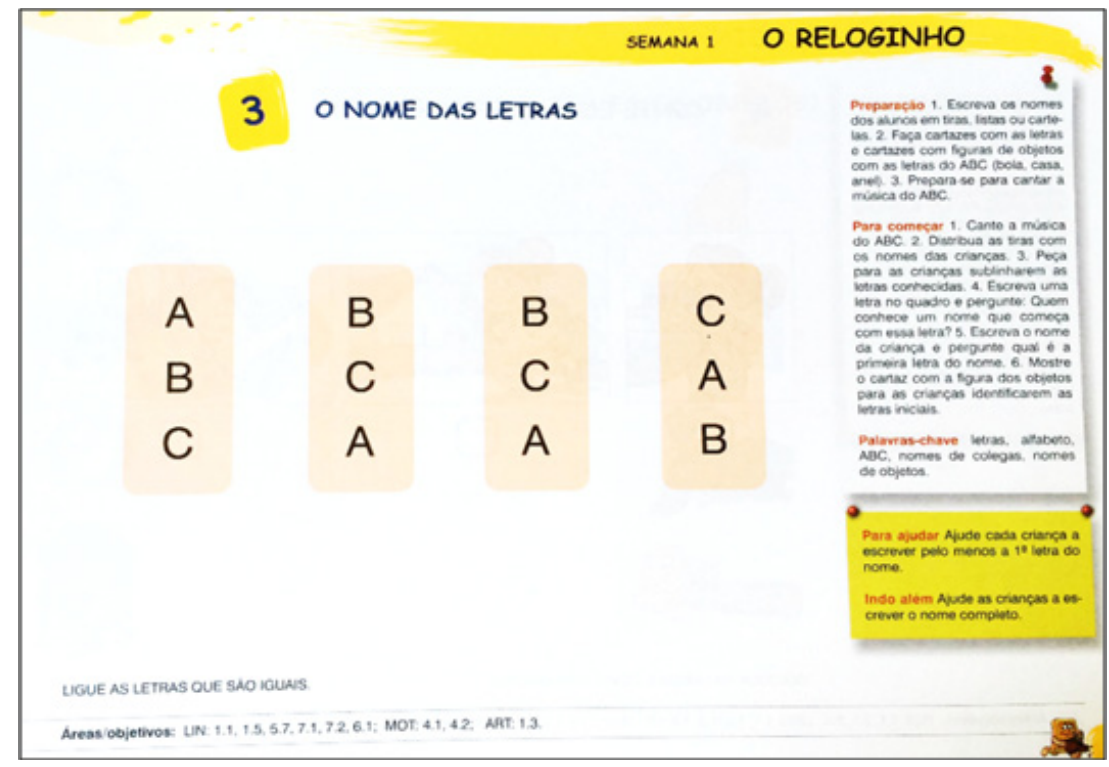

Fonte: Rodrigues, Rocha, Araújo e Oliveira (2010, p. 3).

Figura 2. Ficha do Meu Livro de Atividades

Um outro exemplo pode ser visto na atividade da Figura 3, cuja intenção é a de que a criança memorize o som /c/ e a sua grafia. Para isso, ela deverá repetir 12 (doze) vezes a escrita da letra $\mathrm{C}$ para completar a lacuna presente em cada palavra, algo que pode ser feito mecanicamente, sem qualquer necessidade de reflexão sobre os princípios do sistema de escrita.

Finalmente, ainda no que se refere à proposta declarada no material, assume-se que "A pré-escola não é uma escola que vem antes da outra, e sim um espaço pedagógico diferenciado" (RODRIGUES, ROCHA,
ARAÚJO e OLIVEIRA, 2010, p.V). No entanto, essa concepção é negada quando se propõe o desenvolvimento de habilidades que a criança deveria adquirir como "preparação para atividades escolares futuras" (RODRIGUES, ROCHA, ARAÚJO e OLIVEIRA, p.V). Conforme aponta Soares $(2011$, n.p.), em tal concepção propedêutica, a Educação Infantil é associada, inadequadamente, à ideia de que "essa etapa prepararia a criança para o ensino fundamental. [...] Essa era a visão que se tinha décadas atrás, a de que a criança precisava adquirir certas condições para então aprender a ler e escrever".

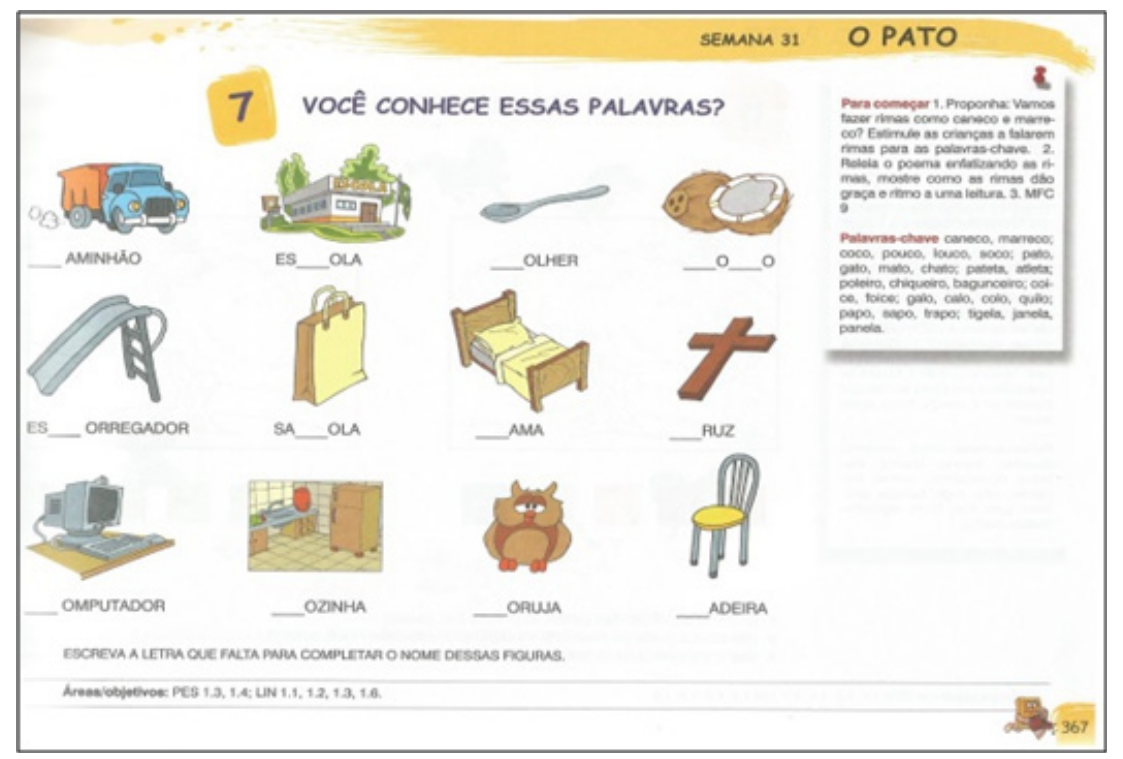

Fonte: Rodrigues, Rocha, Araújo e Oliveira (2010, p. 367).

Figura 3. Ficha do Meu Livro de Atividades 
Após essas considerações, discutiremos, a seguir, mais detalhadamente as perspectivas e propostas para o ensino da leitura e da escrita apresentadas no "Meu Livro de Atividades" do Programa Alfa e Beto Pré-Escola. Para isso, usaremos, a título de ilustração, o material destinado ao Pré II, que corresponde, de modo geral, às turmas de crianças de 5 anos.

\section{Meu Livro de Atividades: perspectivas e propostas para o ensino da leitura e da escrita}

O Programa Alfa e Beto Pré-Escola utiliza o método fônico de alfabetização, o qual toma como ponto de partida o fonema - menor unidade sonora da língua -, que, por meio de um processo de síntese, é combinado a outros fonemas para constituição de unidades maiores (sílabas, palavras, frases e textos). Desse modo, a preocupação incide, principalmente, no reconhecimento dos fonemas nas palavras e na memorização de sua forma escrita. Para isso, propõe-se um conjunto de atividades nas quais as crianças devem identificar determinados fonemas no início, no meio ou no final de palavras, contar o número de vezes em que eles aparecem em uma palavra, reconhecer palavras que comecem com o mesmo fonema, entre outras.

É o que podemos observar, por exemplo, nas atividades da ficha apresentada na Figura 1, na qual se solicita à criança que identifique as palavras que possuem o fonema /s/ localizado em diferentes posições, tal como se observa em: "sapo, rasgar ou estar". Nessa mesma ficha, propõe-se, do lado direito da página, atividades orais que envolvem a adição e o isolamento de fonemas:

1. Beto quer participar da brincadeira. Ele vai dizer os sons, e vocês vão dizer a palavra. CF 7. Beto: /s/ /a/ /i/. - Qual é a palavra? Todos: SAI. 2. Continue com outras palavras-chave. 3. Agora é Alfa que quer brincar. Vejam o que ele propõe. CF 8: SUA, quais são os sons? /s/ /u/ /a/. SUA. Quantos sons? Três (RODRIGUES, ROCHA, ARAÚJO e OLIVEIRA, 2010, p. 269).

Nessas atividades, evidencia-se que a proposta da material parte do pressuposto de que o desenvolvimento de complexas habilidades de consciência fonêmica, que consiste na capacidade de manipular fonemas, constituiria condição para o sucesso na alfabetização. Ignora-se, portanto, os estudos (cf. MORAIS, 2004; MORAIS, 2006) que evidenciam a dificuldade que até mesmo crianças alfabetizadas apresentam para distinguir fonemas em palavras e pronunciá-los de forma isolada. Morais (2013) também constatou que segmentar e pronunciar fonemas em palavras não é uma tarefa simples nem mesmo para crianças ensinadas pelo método fônico e já com hipótese alfabética. As análises qualitativas dos acertos e erros dessas crianças revelaram, ainda, que elas tendiam a pensar sobre a quantidade de letras ou sílabas e não de fonemas.

De fato, a consciência fonológica, que envolve a habilidade de refletir sobre e de manipular as partes sonoras das palavras, contempla desde habilidades mais simples, como segmentar oralmente as sílabas de uma palavra ou reconhecer semelhanças sonoras entre palavras que possuem a mesma sílaba inicial, até habilidades mais complexas e abstratas, como contar fonemas ou identificálos no meio de uma palavra. De modo geral, como observa Morais (2006), diferentemente da consciência fonêmica, a consciência fonológica no nível da sílaba ou da rima desenvolve-se mais cedo e envolve habilidades menos complexas que as do nível do fonema.

Assim, não negamos aqui a importância da criança descobrir na Educação Infantil que as palavras são constituídas de segmentos sonoros que correspondem a segmentos escritos. Nessa direção, alguns autores (cf. MORAIS; SILVA, 2010; SOARES, 2009) têm argumentado que atividades de consciência fonológica que exploram segmentos maiores que o fonema (como sílabas e rimas) podem ser propostas para desenvolver na criança a noção de que a palavra é uma sequência de segmentos sonoros, que, por sua vez, correspondem a segmentos escritos.

Entre tais atividades, os autores supracitados sugerem a exploração de gêneros textuais da tradição oral (parlendas, quadrinhas, trava-línguas, poemas, etc.) e o uso de jogos didáticos que envolvam a análise das partes sonoras das palavras e suas relações com a escrita. Tais propostas são, portanto, muito diferentes de submeter as crianças a atividades de treino fonêmico como as que apresentamos anteriormente ou que as levam a repetir, por exemplo, frases ditas pela professora com pouco ou nenhum sentido ("Magali lambe o livro ilustrado com picolés de laranja, limão e melancia" (RODRIGUES, ROCHA, ARAÚJO e OLIVEIRA, 2010, p.VI), apenas para ensinar um determinado fonema.

Outro aspecto a ser ressaltado em relação ao "Meu Livro de Atividades" é a presença de textos artificialmente produzidos para ensinar a ler, com léxico controlado e frases justapostas. A atividade transcrita a seguir, com orientações para a escrita e leitura de "frases" pela professora, ilustra tal afirmação.

Para começar 1 - Escreva no quadro e depois fale a frase, reforçando o som das palavras: Que susto! O senhor frade Serafim sumiu! Onde foi o senhor frade Serafim? Eu sei. O sino bateu e ele correu. Saiu para procurar os sapatos rasgados que o gato Simão escondeu. Simão, seu gato safado, comeu os meus 
sapatos? 2. Repita a frase com as crianças. 3. Mostre a cartela do $\mathrm{S}$ com o par de sapatos virado para as crianças e peça que repitam a palavra SAPATO. Repita a palavra reforçando: sapato (RODRIGUES, ROCHA, ARAÚJO e OLIVEIRA, 2010, p. 267).

Pseud. textos semelhantes ao exemplificado acima são frequentes no "Meu Livro de Atividades". Assim, ao longo do ano, as crianças vão sendo expostas a textos nos quais o sentido do que se diz deixa de ser importante, já que o que conta é a presença de palavras que reforcem a pronúncia do fonema que se quer ensinar. Tais propostas, além de artificializar inteiramente o ato da leitura, considerando-o como uma mera atividade de decodificação, faz um desserviço ainda maior ao ensinar as crianças que os textos não comunicam nada que valha a pena ser lido.

Como observa Soares (2009), a leitura frequente de histórias é a principal e indispensável atividade de letramento na Educação Infantil. No entanto, segundo a autora, outros gêneros de texto podem e devem ser objeto de leitura para as crianças. Assim, nessa etapa de ensino, podemos, por exemplo, ler uma reportagem para ampliar o conhecimento sobre tubarões no contexto de um projeto em que as crianças estão envolvidas ou ler uma notícia no jornal para obter informação sobre um tema que seja de interesse das crianças, entre tantas outras possibilidades de leitura bem diferentes das apresentadas pelo livro analisado.

Nessa perspectiva, a Educação Infantil deve contribuir para inseriras crianças no mundo da leitura, propiciando a compreensão de que os textos dizem algo interessante ou necessário para que realize alguma atividade e que, desse modo, demandam um esforço de construção de sentidos. Consideramos que essa é uma aprendizagem fundamental que pode e deve ocorrer na Educação Infantil. Porém, para isso é preciso levar as crianças a participar de práticas sociais mediadas pela leitura de textos que circulam socialmente e atendem a uma determinada finalidade sócio discursiva. Em outras palavras, é preciso desde cedo entender a leitura de textos como uma atividade ativa e criativa de construção e produção de sentidos (cf. MARCUSCHI, 2008; SOLÉ, 1998).

Para concluir, o trabalho no eixo da produção de textos proposto no livro didático apresenta igualmente situações pouco significativas para as crianças, desconsiderando essa atividade como uma ação sócia discursiva que visa a atingir determinada finalidade e interlocutor. É o que podemos observar no exemplo a seguir (Figura 4), no qual se solicita que as crianças escrevam uma carta a partir de um "passeio" sugerido para se realizar "dentro da escola" ou para "visitar uma caixa do correio".

Como vemos na atividade apresentada na Figura 4, a carta a ser produzida não tem destinatário e não serve para comunicar algo a alguém distante. Trata-se, muito mais, de um pretexto para contar sobre um suposto "passeio" realizado e o que foi aprendido sobre cartas e caixas do correio. Ao contrário dessa situação descontextualizada de escrita, no cotidiano de uma sala de Educação Infantil, também são múltiplas as situações que podem ser aproveitadas para evidenciar os usos e as funções sociais da escrita. Assim, propostas de produção coletiva

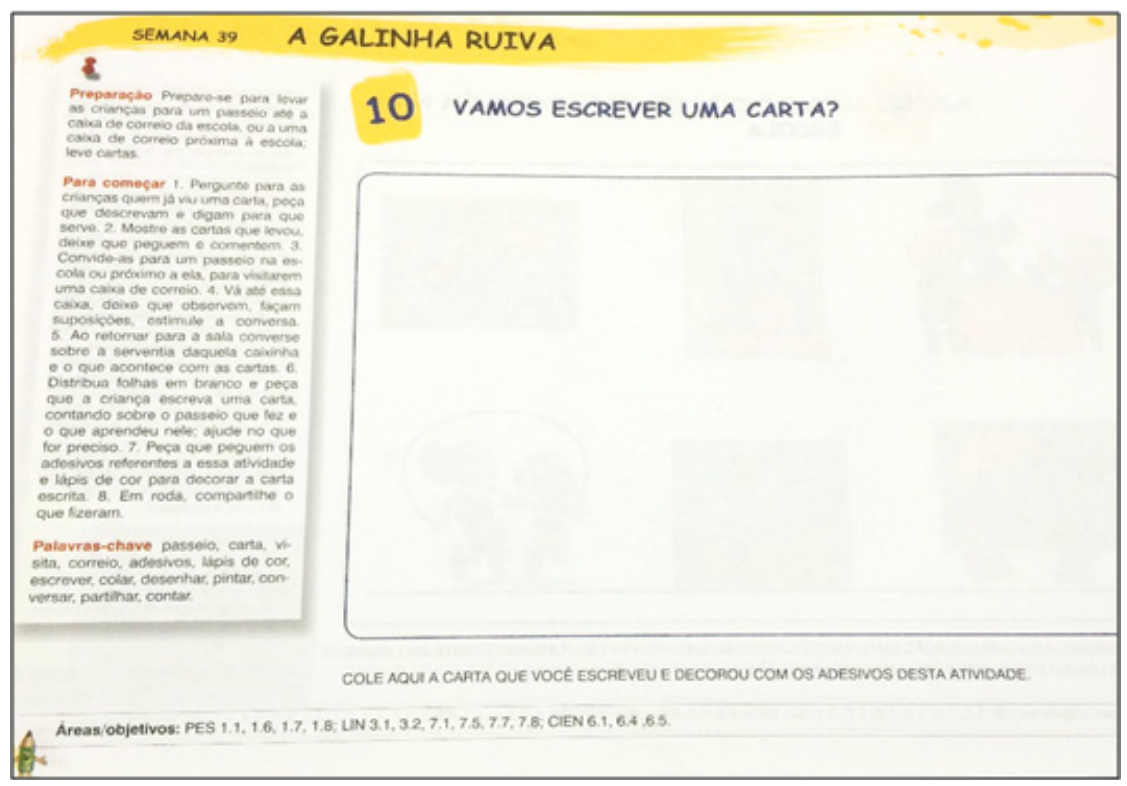

Fonte: Rodrigues, Rocha, Araújo e Oliveira (2010, p. 466).

Figura 4. Ficha do Meu Livro de Atividades 
ou individual de um cartão de aniversário para alguém ou de um bilhete para os pais solicitando material para um lanche coletivo seriam, certamente, não apenas mais apreciadas pelas crianças, como cumpririam de modo mais apropriado o papel de ensinar para que e como se escreve.

\section{CONSIDERAÇÕES FINAIS}

Entendemos que uma das funções da Educação Infantil é contribuir para aproximar as crianças dos livros e ampliar seus conhecimentos, estimulando a sua curiosidade natural para descobrir e entender o mundo. Para isso, é fundamental que elas gostem de estar na escola. Obrigá-las a realizar uma bateria enorme de atividades repetitivas que pouco ou nada tem a ver com suas vivências irá, certamente, na direção contrária a que pretendemos.

Além disso, parece-nos importante considerar que nessa primeira etapa da Educação Básica há, comumente, maior flexibilidade na seleção de temas a serem tratados na escola, sendo possível aproveitar a motivação das crianças para aprofundar tópicos que podem estar bem distantes das temáticas propostas em livros didáticos. Nesse sentido, ao adotar um livro, perde-se a chance de usufruir dessa maior liberdade de ação que a Educação Infantil, potencialmente, proporciona para professoras e crianças.

Porém, se a decisão for a de adotar um livro didático, há uma série de questões que precisam ser refletidas. Assim, é necessário, por exemplo, identificar a concepção de ensino e aprendizagem que o livro veicula: não apenas aquela explicitada na apresentação do material, mas, sobretudo, que transparece nos tipos de atividades propostos ao longo da obra. Em segundo lugar, cabe discutir e planejar o uso que será feito do livro: ele será usado apenas na escola? De que forma? Em pequenos grupos, de modo que a professora possa realmente acompanhar as crianças e intervir durante a realização das atividades, enquanto outros grupos estão envolvidos em propostas mais livres? O material também será usado em casa? Qual a frequência com que o livro será usado na escola ou em casa? De que modo os temas e as atividades propostas no livro podem ser inseridos ou integrados no currículo vivido pelas crianças? Nesse sentido, também cabe perguntar: todas as atividades do livro precisam ser, necessariamente, feitas pelas crianças e na ordem apresentada no livro? Também é fundamental observar como as crianças reagem diante das atividades propostas: elas compreendem os comandos do livro? Mostram-se motivadas para realizar o que é solicitado?

Como vemos, um uso reflexivo e flexível de livros didáticos nessa primeira etapa da escolaridade requer conhecer muito bem o material a ser adotado e tomar uma série de decisões que irão, sem dúvida, afetar a natureza e a qualidade do trabalho pedagógico oferecido às crianças. Infelizmente, esse tipo de uso do livro parece não ocorrer. Observações em turmas do último ano da Educação Infantil de escolas da rede privada têm indicado que as atividades do livro didático ocupam a maior parte do tempo das crianças na escola, sendo usado diariamente e seguido página a página pelas professoras (cf. LIMA, 2010; CABRAL, 2013).

Temos a impressão, nesses casos, que o problema não parece estar apenas no uso que se faz do livro, mas na própria concepção de Educação Infantil que orienta o trabalho pedagógico nessa etapa. Ou seja, nas observações descritas nos estudos agora citados, é possível supor que o livro apenas tornou o trabalho mais "prático" para as professoras, já que, provavelmente, substituiu o caderno ou as fichas de atividade com lápis e papel que as crianças seriam solicitadas a fazer, caso o livro didático não estivesse disponível.

Por fim, sob nosso ponto de vista, em vez de solicitar aos pais a compra de livros didáticos ou sistemas apostilados ou investir recursos públicos na compra desse material cuja qualidade é, no mínimo, questionável, os gestores deveriam investir na formação continuada de professores, bem como em condições dignas de salários, espaço físico, equipamentos e materiais que estimulem a permanência e a atração de docentes competentes e comprometidos com a educação das crianças.

\section{REFERÊNCIAS}

BRANDÃO, Ana Carolina Perrusi; CARVAlHO, Maria Jaqueline Paes. As fichas de atividades de linguagem escrita na educação infantil. In: BRANDÃO, Ana Carolina Perrusi; ROSA, Ester Calland de Souza (Org.). Ler e escrever na Educação Infantil: discutindo práticas pedagógicas. Belo Horizonte: Autêntica, 2010.

BRANDÃO, Ana Carolina Perrusi; LEAL, Telma Ferraz. Alfabetizar e letrar na Educação Infantil: O que isso significa? In: BRANDÃO, Ana Carolina Perrusi; ROSA, Ester Calland de Souza (Org.). Ler e escrever na Educação Infantil: discutindo práticas pedagógicas. Belo Horizonte: Autêntica, 2010.

BRANDÃO, Ana Carolina Perrusi; ROSA, Ester Calland de Souza (Org.). Ler e escrever na Educação Infantil: discutindo práticas pedagógicas. Belo Horizonte: Autêntica, 2010.

BRANDÃO, Ana Carolina Perrusi; SELVA, Ana Coelho Vieira. O livro didático na educação infantil: reflexão versus repetição na resolução de problemas matemáticos. Educação e Pesquisa, São Paulo, v. 25, n. 2, p. 69-83, jul./dez. 1999.

BRASIL. Diretrizes Curriculares Nacionais para a Educação Infantil. Brasília: MEC/SEB, 2010.

CABRAL, Ana Catarina Pereira dos Santos. Educação Infantil: um estudo das relações entre diferentes práticas de ensino e conhecimentos das crianças sobre a notação alfabética. 
2013. 298 f. Tese (Doutorado em Educação) - Programa de PósGraduação em Educação, Centro de Educação, Universidade Federal de Pernambuco, 2013.

CRUZ, Edneri Pereira. Classificação na Educação Infantil: O que propõem os livros e o como é abordada por professores. 2012. 170f. Dissertação (Mestrando em Educação Matemática e Tecnológica) - Programa de Pós-Graduação em Educação Matemática e Tecnológica, Centro de Educação, Universidade Federal de Pernambuco, 2012.

FERREIRO, Emília. Reflexões sobre alfabetização. 23. ed. São Paulo: Cortez, 1995.

LIMA, Amara Rodrigues. Educação infantil e alfabetização: um olhar sobre diferentes práticas de ensino. 2010. $138 \mathrm{f}$. Dissertação (Mestrado em Educação) - Programa de PósGraduação em Educação, Centro de Educação, Universidade Federal de Pernambuco, 2010.

LORENZO, Nara Olívia. O livro didático para a Educação Infantil: análise da Coleção Buriti Mirim. 2014. Trabalho de Conclusão de Curso (Graduação em Pedagogia) - Universidade Federal de Pernambuco, 2014.

MARCUSCHI, Luiz Antônio. Produção textual, análise de gêneros e compreensão. São Paulo: Parábola Editorial, 2008.

MORAIS, Artur Gomes de. A apropriação do sistema de notação alfabética e o desenvolvimento de habilidades de reflexão fonológica. Letras de Hoje, Porto Alegre, v. 39, n. 3, p. 35-48, 2004.

MORAIS, Artur Gomes de. Consciência fonológica e metodologias de alfabetização. Presença Pedagógica, v. 12, p. 58-67, 2006.

MORAIS, Artur Gomes de. Crianças com hipótese alfabética, ensinadas pelo método fônico, não conseguem resolver tarefas de consciência fonêmica. In: CONGRESO LATINOAMERICANO PARAODESARROLLODELALECTURAYLAESCRITURA
Y IV FORO IBEROAMERICANO DE LITERACIDAD Y APRENDIZAJE, 7., 2013, Puebla. Anais... Puebla: Red de Cultura Escrita y Comunidades Discursivas, 2013. (1 CD-ROM).

MORAIS, Artur Gomes de; SILVA, Alexsandro da. Consciência fonológica na Educação Infantil: desenvolvimento de habilidades metalinguísticas e aprendizado da escrita. In: BRANDÃO, Ana Carolina Perrusi; ROSA, Ester Calland de Souza (Org.). Ler e escrever na Educação Infantil: discutindo práticas pedagógicas. Belo Horizonte: Autêntica, 2010.

NASCIMENTO. Maria Letícia Barros Pedroso. As políticas públicas de educação infantil e a utilização de sistemas apostilados no cotidiano de creches e pré-escolas públicas. Revista Brasileira de Educação, v. 17, n. 49, p. 59-80, jan.-abr. 2012.

RODRIGUES, Anna Cristina de Araújo; ROCHA, Denise Silva. ARAÚJO e OLIVEIRA, João Batista. Programa Alfa e Beto para Pré-Escola: livro de atividades II. Brasília: Instituto Alfa e Beto, 2010.

SOARES, Magda. Aprendizagem lúdica. Revista Educação, 2011. Disponível em: <http://revistaeducacao.uol.com.br/ textos/0/aprendizagem-ludica-240352-1.asp >. Acesso em: 15 ago. 2014.

SOARES, Magda. Alfabetização e letramento na Educação Infantil. In: Revista Pátio Educação Infantil, ano VI, n. 20, Porto Alegre: Artmed, jul.-out. 2009. Disponível em: <http://falandodospequenos.blogspot.fr/2010/04/ alfabetizacao-e-letramento-na-educacao.html>. Acesso em: 20 out. 2015.

SOLÉ, Isabel. Estratégias de leitura. Porto Alegre: Artmed, 1998.

Recebido em 29-04-2016. Aprovado em 06-06-2017. 